\title{
LES RÉPUBLIQUES MARITIMES ITALIENNES ET LE COMMERCE EN SYRIE-PALESTINE (XI-XIII ${ }^{\circ}$ SIECLES)
}

\author{
Michel BALARD \\ Université de Paris I-Sorbonne \\ (France)
}

\begin{abstract}
SOMMAIRE
1. Les premiers contacts des Italiens avec le Levant.- 2. L'implantation des Italiens en Syrie-Palestine.- 3. Les chartes concédées aux Italiens: répartition chronologique.- 4. La localisation des comptoirs italiens en Syrie-Palestine.- 5. Les privildges accordes aux Italiens: leur nature.- 6. Marchands italiens et colons.- 7. L'organisation des activités commerciales.- 8. Le trafic.
\end{abstract}

Pendant près de quatre siècles, les ressortissants des républiques maritimes italiennes ont joué un rôle préponderant dans la vie économique de la Palestine médiévale. Des premières croisades jusqu'à la veille des grandes découvertes, leurs flottes ont régulièrement sillonné la Méditerranée pour déposer hommes d'affaires et marchandises dans les ports du Sahil, et y prélever tout ce que pouvait y laisser le trafic venu du Croissant fertile. De 1098 à 1291, cette activité a été stimulée par la possession d'avantages territoriaux et commerciaux de grande ampleur dans les villes détenues par les Francs au point que, selon certaines traditions historiogra- 
phiques ${ }^{1}$, le renouveau du commerce occidental du Levant devrait être attri bué aux effets des croisades. Les marchands italiens auraient accompagné les gens de guerre; l'aide de leur flotte dans la conquête des villes côtières aurait eu pour immédiate contre-partie des concessions territoriales et douanières donnant à l'activité mercantile un élan sans précédent.

\section{LES PREMIERS CONTACTS DES ITALIENS AVEC LE LEVANT}

Aujourd'hui de telles conceptions sont remises en cause. L'exploitation des documents de la Geniza du Caire nomtre que les hommes d'affaires italiens n'ont pas attendu les croisades pour fréquenter les ports du Proche-Orient. Les Amalfitains, en relations d'affaires avec les Fatimites de Berberrie, suivent ceux-ci en Egypte après 969. Il est établi par un texte de 996 que pres de deux cents marchands d'Amalfi se trouvaient au Caire, où ils furent victimes de la vindicte populaire, à la suite de l'incendie d'une flotte préparée contre Byzance ${ }^{2}$. Les besoins des Fatimides en bois et en fer sont tels que l'incident est vite classé et les affaires reprennent. Quelques décennies plus tard, les Génois à leur tour fréquentent Alexandrie et le Vieux Caire; une lettre de la Geniza établit que des les années 1070 des navires génois relachent à Alexandrie, tandis que, selon une autre, des marchands de la Superbe ont été emprissonnés au Caire par le sultan al-Malik al-Afdal au tout début du XII siecle $^{3}$.

\footnotetext{
'C'est par exemple l'interpretation, certes nuancé de W. HEYD, Histoire du commerce du Levant au Moyen Age, (2 vol., Amsterdam2, Hakkert, 1967), I, pp. 124-125, 132-133, de A. SCHAUBE, Handelsgeschichte der romanischen Volker des Mittelmeergebietes bis zum Ende des Kreuzzoge, München-Berlin, 1906. L'historiographie marxiste etablit un lien direct entre l'organisation des croisades et la recherche de nouveaux marches par les hommos d'affaires italiens: cf. Karl-E. WERNER, Die Kreuzzugidee in Mittelalter, in "Wissenschaftliche Zeitochritt der Karl Marx Univereität Leipzig", 5 (1957-1958), pp. 135-140.

${ }^{2} \mathrm{Cl}$. CAHEN, Un sexte peu connu relatif au commerce oriental d'Amalfi an $\boldsymbol{X}$ sizcle, "Anchivio storico per le province napoletane", n.s., XXXIV (1953-1954), pp. 1-8, repris in Turco-Byzansina et Oriens christianus, London, Variorum Reprints, 1974, étude 2 A. IDEM, Le commerce d'Amalfi avant, pendans es apres la croisade, in "Comptes-rendus de l'Acedémie des Inscriptions a Belles-Lottres", Paris, 1977, pp. 291-301.

'S.D. GolTEIN, A Mediterranean Society. The Jewish Communities of the Arab World as portrayed in the Documents of the Cairo Geniza. I: Economic Foundations, Berkeley-Los Angeles, 1967, pp. 318, 45; E. AsHTOR, A Social and Economic History of the Near East in the Middle Ages, London, 1976, Pp. 196, 333 and B.Z. KEDAR, Mercanti genovesi in Alessandria d'Egitto negli anni sessansa del secolo XI, in "Miscellanea di Studi storici" II, Genova, Collana storica di Fonti e Studi dirette da Geo Pistarino, 1983, pp. 19-30.
} 
Depuis l'Egypte, les hommes d'affaires italiens se rendent aussi en Syrie-Palestine dans les décennies qui précèdent la Première Croisade. Ici encore, les Amalfitains sont des précurseurs. Vers 1040, grâce à une concession du calife fatimide al-Mostancir (1035-1094), des marchands d'Amalfi, sous la conduite du célebre comte Mauro, s'installent à Jérusalem à l'endroit ou se trouvait jadis l'hospice latin; ils y fondent une maison pour accueillir les pelerins originaires d'Amalfi ainsi que l'église Sainte-Marie latine, au sud du Saint-Sépulcre. Ces établissements confiés à la garde de moines amalfitains sont, on le sait, a l'origine lointaine de l'ordre de l'HOpital. Vers la même époque, des Amalfitains figurent sans doute parmi les Ram que Nasir-i-Khusrau dit fréquenter le port de Tripoli de Syrie 4 . On les rencontre également à Antioche où existent un hospice pour les pèlerins, fondé, aux dires d'Aimé du Mont-Cassin, par le même Mauro di Maurone, et une "ruelle des Amalfitains" citée dans le privilege accordé aux Génois en 1101 et qui porte donc témoignage de la présence ancienne des Amalfitains dans la capitale de la Syrie du Nords.

Les ressortissants des autres républiques maritimes, peut-être englobés sous le qualificatif de Ram dans les documents de la Geniza, sont beaucoup plus rarement cités dans les villes de Syrie-Palestine avant la Premiere Croisade. Le pelerinage de Godefroy de Bouillon sur une nef génoise avant 1095 est une légende forgée par Caffaro pour mettre en valeur le rôle éminent de ses compatriotes au moment de la prise de Jérusalem ${ }^{6}$. D'autre part, d'après la chronique du pseudo-Ingulf, un faux rédigé a la fin du Moyen Age, le grand pelerinage de 1065 aurait utilisé pour revenir en Occident des navires génois venus commercer à Jaffa et dans divers ports

\footnotetext{
'Cl. Cahen, in Comptes-rendus, pp. 293; A.O. Citareun, Patterns of Medieval Trade. The commerce of Amalfi before the Crusades, in "Joumal of Economic History", 28 (1968), pp. 531-555; J. RILEY-SMTT, The Knights of Saint John in Jerusalem and Cyprus (11001350), London, 1967, pp. 34-36; B. FIGuUOLO, Amalfi e il Levante nel Medioevo, in "I Comuni italiani nel regno crociato di Gerusalemme", ed. G. AIRALDI-B.Z. KEDAR, Genova, 1986, pp. 590-593.

'AMATO DI MONTECASSINO, Storia dei Normanni, ed. V. de Bartholomaeis, Roma, Fonti per la storia d'Italia, 1935, pp. 341-342. Voir W. HEYD, Histoire du commerce, p. 103; R. ROHRICHT, Regesta regni hierosolymitani 1097-1291, New-York2, Burt Franklin, 1960, pp. 63-64; C. IMPERUIE DI SANT'ANOELO, Codice diplomasico della Repubblica di Genova, (3 vol., Roma, Istituto atorico italiano por il Modioovo, 1936-1942), I, p. 17.

'CAFraro, De liberatione civicatum Orientis liber in "Annali genovedi di Caffaro o de' moi continuatori", Ed. L.T. Belgrano-C. Imperialo di Sant'Angelo, (5 vol., Roma, Fonti per la storia d'Italia, 1890-1929), I: 99-100.
} 
du Levant ${ }^{7}$. Bien que suspectes, ces deux notices ont pu néanmoins utiliser des sources alors connues attestant des relations maritimes entre Gênes et la Syrie-Palestine avant la fin du $\mathrm{XI}^{\circ}$ siecle ${ }^{8}$.

Il serait étonnant qu'il n'en soit pas de même pour les Vénitiens, solidement établis dans l'empire byzantin et considérés eux aussi parmi les Rum qui fréquentent les ports du Levant au $\mathrm{XI}^{\circ}$ siècle. En revanche il est impossible de dire si les Pisans venaient eux-aussi en Syrie-Palestine avant 1095, les plus anciens témoignages étant contemporains de la Premiere Croisade. A cette exception près, il est aujourd'hui établi que les premiers contacts commerciaux des Italiens avec le Levant sont bien antérieurs à 1095. S'ils restent limités, c'est sans doute que Constantinople et Alexandrie offraient aux marchands des opportunités plus grandes de mener leurs affaires, dans la mesure où ces deux villes étaient soit le point terminal de grands axes du commerce international -par la mer Noire d'un côté, par la mer Rouge et le Nil de l'autre- soit des centres de diffusion des produits de l'artisanat local. Elles réalisent toutes deux le lien indispensable entre le commerce terrestre et le commerce maritime, ce qui justifie la présence précoce dans ces deux villes des hommes d'affaires italiens.

\section{L'implantation des Italiens EN Syrie-Palestine}

Il n'est pas certain que les expéditions de la croisade et l'implantation des Francs en Syrie-Palestine changent immédiatement cet état de choses. Les premiers contacts des Italiens avec la Terre Sainte se placent en effet sous le signe de la violence. L'état de guerre qui caractérise les deux premières décennies de l'expansion occidentale en Syrie n'est pas favorable a l'essor des affaires; le trafic des ports ne peut être qu'entravé par l'établissement d'un frontiere entre la Syrie intérieure musulmane et les régions franques ${ }^{9}$. D'autre part, les marchands italiens sont partagés entre le désir de s'approprier l'or et les richesses des pays conquis aux dépens des $\mathrm{Mu}$ sulmans, et le souci de ne point perdre les positions commerciales jusque là 514.

'Ingulphi Historia in "Rerum Anglicarum Scriptores", éd. M. SAVILE, London, 1956, p.

${ }^{8}$ B.Z. KEDAR, in Miscellanea di Studi storici, p. 28.

${ }^{9} \mathrm{Cl}$. CAHEN, Orient et Occident au termps des croisades, Paris, Aubier, 1983, p. 107. 
acquises dans d'autres pays musulmans. Mais n'ayant pas les mêmes intérêts, chacune des républiques maritimes adopte des attitudes divergentes et participe inégalement aux opérations de la croisade.

Amalfi s'est bien gardée d'y prendre part. L'attaque normande de 1096 contre la ville n'explique pas à elle seule cette abstention, d'autant qu'au cours des années ultérieures les Amalfitains continuent à ne pas se manifester. Sans doute avaient-ils des raisons de craindre que les entreprises des croisés, fort aléatoires, leur ferient perdre les avantages acquis tant en Egypte qu'en Syrie-Palestine. Il est remarquable, en tout cas, qu'au cours du XII ${ }^{e}$ siècle, le commerce amalfitain s'y maintient, indépendamment des évènements liés aux croisades ${ }^{10}$.

L'attitude de Venise ne differe guère. Solidement établis dans l'empire byzantin, les marchands de la Lagune pouvaient craindre eux aussi de perdre, par un rapprochement avec les Normands, ennemis de Byzance, les faveurs impériales, et de compromettre également les premiers succès commerciaux obtenus avant la croisade dans le monde musulman. Aussi faut-il attendre que se confirment les victoires des Francs pour voir les Vénitiens se joindre, bien tardivement, au mouvement général. En juillet 1099 part une première expédition conduite par le fils du doge et l'évêque de Castello. La flotte de deux cents vaisseaux hiverne à Rhodes, après s'être débarrassée d'une cinquantaine de vaisseaux pisans qui voulaient également y jeter l'ancre. Elle n'arrive à Jaffa qu'en juin 1100. Godefroy de Bouillon requiert alors son aide pour assiéger Acre, en échange de futures concessions territoriales et fiscales. Mais, pour des raisons obscures les forces vénitiennes se détournent vers Haïfa et ne semblent pas jouer un grand rôle dans la prise de cette ville ${ }^{11}$.

Dix ans s'écoulent avant que Venise intervienne à nouveu dans les affaires de Terre Sainte. A la fin de l'année 1110, une centaine de navires placés sous le commandement du doge Falier, coopère avec la flotte du roi de Norvège, Sigurd, à la prise de Sidon ${ }^{12}$. Le Vénitiens reçoivent alors du

${ }^{10} \mathrm{Cl}$. CAHEN, Orient et Occident, p. 80; B. FIglJuOL, in I Comuni italiani, pp. 608-613.

"Donald-E. QUEUER, Irtne B. KATELE, Venice and the conquest of the Latin Kingdom of Jerusalem, in "Studi veneziani", 12 (1986), Pp. 23-26; Marie-Luise FAVREAU-LIUE, Die Italiener im Heiligen Land vom ersten Kreuzzug bis zum Tode Heinrichs von Champagne (1098-1197), Amsterdam, Adolf M. Hakkert, 1989, pp. 62-79. 133.

${ }^{12}$ QUeurer-Katele, Studi veneziani, pp. 28-29; FAVREAU-LIUE, Die Italiener, pp. 130 
roi Baudouin Ier une rue et un marché a Acre. Douze ans plus tard, alors que la conquete franque semble bien assise, le doge Domenico Michiel répond a l'appel de Baudouin II. Il lance une flotte de 120 navires qui prennent part au siège de Tyr. Cet engagement naval et militaite massif vaut à Venise la première concession d'une véritable exterritorialité dans le Levant, sous la forme du pactum Warmundi, un traité concédé par le patriarche de Jérusalem Gormond. Le roi Baudouin II en donne confirmation deux ans plus tard, le 2 mai $1125^{13}$. Venise qui dans les premieres années de la conquete s'est abstenue de toute participation, obtient ainsi tardivement des privilèges bien supérieurs à ceux qui ont été concedés aux deux autres républiques maritimes italiennes.

Pise avait beaucoup moins à perdre. Elle était alors favorable au parti normand et n'avait guere d'intérêt a Byzance ou en Syrie-Palestine. Elle ne répond toutefois a l'appel pontifical que quatre ans après le concile de Clermont. Trois flottes successives partent vers l'Orient: celle de Daimbert qui arrive après la prise de Jérusalem en juillet 1099 et aide Bohémond à s'emparer de Laodicée; une seconde qui s'oppose aux Vénitiens dans les parages de l'île de Rhodes, au cours de l'hiver 1099-1100; une troisieme qui parvient à Jaffa a Paques 1101. Ces diverses forces participent au siège de Laodicée, à la prise d'Arsuf et de Césarée en avril et mai 1101, à celles de Gibelet en avril 1104 et d'Acre en mai de la même année ${ }^{14}$. De ces entreprises, les Pisans tirent un profit réduit: la brouille rapide entre leur chef, l'archeveque Daimbert, et le roi de Jérusalem Baudouin Ier differe toute concession dans le royaume. Seuls les Normands d'Antioche récompensent leurs alliés en leur accordant en 1108 des privilèges a Antioche et Laodicée.

Gênes, en revanche, paraît être la grande bénéficiaire d'une participation massive et constante à la conquête franque. La prédication de la

\footnotetext{
${ }^{13}$ G.L.F. TAFEL-G.M. THOMAS, Urkunden zur alteren Handels- und Staatsgeschichte der Republik Venedig mit besonderer Berücksichtigung auf Byzanz und die Levante, (3 vol., Wien, 1856-1857, réimpr. Amsterdam, Hakkert, 1964), I, pp. 84-89. Une meilleure édition est donnée par Marco POZZA, Venezia e il Regno di Gerusalemine dagli Svevi agli Angioini, in "I Comuni italiani", pp. 373-379. Voir également QUELLER-KATELE, Studi veneziani, pp. 32-38; FAVREAU-LILUE, Die Italiener, pp. 137-149; Joshua PRAWER, The Italians in the Latin Kingdom, in "Crusader Institutions", Oxford, Clarendon Press, 1980, pp. 221-226.

${ }^{14}$ Catherine OTtEn-FrouX, Les Pisans en Orient de la première Croisade d 1406, Thise de $3^{\circ}$ cycle, (2 vol., Université Paris 1, 1981), I, pp. 19-38; Marco TANGHERONI, Pisa e il regno crociato di Gerusalemme, in "I Comuni italiani", pp. 497-521; FAVREAU-LIUE, Die lialiener, pp. 51-61.
} 
croisade y a un succès immédiat. Les citoyens, regroupés en une compagna que dirigent de riches notables, arment plusieurs flottes successives. Debarqués à Port Saint Syméon, à l'embouchure de l'Oronte, ils combattent vigoureusement sous les murs d'Antioche et de Laodicee et participent au pillage. L'annaliste Caffaro est ébloui par l'argent, l'or et les vêtements de prix abandonnés par l'armée de Kerbogha ${ }^{15}$. Les deux frères Guglielmo et Primo Embriaci, capitaines de deux galères génoises dont ils utilisent le bis pour fabriquer des machines de siège, jouent un rôle décisif dans la prise de Jérusalem, au point que Caffaro attribue à ses concitoyens la conquête de la ville et le massacre d'innombrables Sarrasins ${ }^{16}$. De même, la prise de Césarée doit beaucoup aux exploits de Wilielmus Caputmalli, consul de l'armée génoise; la ville est saccagée et les Génois emportent un énorme butin qu'ils se partagent, à raison de 48 sous de Provins et 2 livres de poivre par soldat ${ }^{17}$. De 1098 a 1110 les Génois ont ainsi collaboré, d'abord à titre privé, puis de manière officielle, à toutes les entreprises de la conquête et ont obtenu en retour d'importantes concessions dans les trois Etats francs de Syrie-Palestine ${ }^{18}$.

Celles-ci ne sont pourtant pas à la mesure de l'aide fournie. Bien que plus tôt récompensées par les autorités franques, Gênes et Pise apparaissent moins bien pourvues que Venise qui a su obtenir des concessions plus larges et plus diversifiees. A quels facteurs attribuer ces succès? non point à la plus longue expérience des Vénitiens en matière coloniale $-\mathrm{a}$ Byzance, en effet, ils ne jouissent d'aucun privilège d'exterritorialité- mais plutôt à la forme même du gouvernement ducal qui assure au doge une permanence, dont ne peuvent se prévaloir à cette date les autres républiques maritimes italiennes. A Gênes, la Compagna devient lentement un organisme public; même constituée en tant que tel, les mutations fréquentes de ses élites dirigeantes l'empêchent d'avoir la meme volonté politique et la même continuité de vues que le gouvernement d'un doge elu à vie ${ }^{19}$. En ce qui

\footnotetext{
${ }^{15}$ CAFFARO, De liberatione civilatum, I, p. 106.

${ }^{16}$ CAFFARo, De liberatione civitatum, I, p. 110; Franco CARDINI, Profilo di un crociato: Guglielmo Embriaco, in "Archivio storico italiano", 136 (1978), pp. 405-446.

${ }^{17}$ L.T. Belgrano, Annali genovesi, I, pp. 9-13.

${ }^{18}$ Sur l'attitude des trois républiques maritimes au moment de la Conquête, voir CAHEN, Orient et Occident, pp. 78-79.

${ }^{19}$ La remarque est développée par Geo PISTARINo, Genova e il Vicino Oriente nell 'epoca del regno latino di Gerusalemine, in "I Comuni italiani", pp. 76-82
} 
concerne Pise, la même faiblesse structurelle a pu jouer, ainsi que les effets néfastes de la rivalité entre Daimbert et Baudouin Ier.

Les chartes délivrées aux trois républiques maritimes dans les années qui suivent la conquête franque déterminent la situation respective de leurs ressortissants au cours du XII ${ }^{e}$ siecle dans les villes de Syrie-Palestine. Mais il n'est pas certain qu'elles aient été totalement appliquées. Les Italiens étaient-ils suffisamment nombreux pour occuper les quartiers urbains que leur concédaient les princes francs? Le don d'une église, d'un fondouk, d'un bain, d'un four, d'une rue ou d'un ensemble de maison ne signifie pas nécessairement que se crée un quartier placé sous la juridiction d'un représentant de la métropole, ni que se développe par cette création un courant commercial d'importance. D'autre part, il faut etre attentif aux faux diplômes qui ont pu être forgés longtemps après la conquête, pour justifier les prétentions des Communes italiennes, au moment où celles-ci exercent un poids décisif dans la politique des Etats francs ${ }^{20}$. Enfin, il faut bien considérer que si tous les privilèges concédés par le roi de Jérusalem ou le prince d'Antioche avaient été effectivement appliqués, ces souverains se serient dépouillés d'une part importante de leurs prérogatives et auraient perdu les villes côtières de leur Etat au profit des républiques maritimes italiennes. D'ou leurs efforts, au moins au cours du $\mathrm{XI}^{\circ}$ siècle, pour revenir sur des clauses imprudemment accordées au moment de la conquête ${ }^{21}$.

\section{LES CHARTES CONCÉDÉES AUX ITALIENS: RÉPARTITION CHRONOLOGIQUE}

Ces réserves faites, les chartes qui fondent les droits des ressortissants italiens en Syrie franque ne se répartissent pas indifféremment tout au long du XII ${ }^{e}$ siècle. Des temps forts succedent à une longue inertie diplo-

\footnotetext{
${ }^{20}$ CAHEN, Orient et Occident, pp. 79, 108. Voir par exemple l'hypercriticisme de Hans-E. MAYER et Marie-Luise FAVREAU, Das Diplom Balduins I fur Genua und Genuas Goldene Inschrift in der Grabeskirche, in "Quellen und Forschungen aus italienischen Archiven und Bibliotheken", 55.56 (1976), pp. 22-95; contre cette thèse, Benjamin Z. KEDAR, Genoa's Golden Inscription in the church of the Holy Sepulchre: a case for the defence, in "I Comuni italiani", pp. 317-335.

21 Joshua PRAWER, The Italians in the Latin Kingdom, in "Crusader Institutions", pp. 218 219; IDEM, Colonialismo inedievale. Il regno latino di Gerusaleınme, Roma, Jouvence, 1982, pp. 114-115.
} 
matique. Les premiers privileges se regroupent entre 1098 et 1130 et sont liés directement à la conquête. Les premiers rois de Jérusalem réduits à leurs seules forces sont impuissants; le concours des flottes italiennes leur est indispensable pour s'emparer des places côtières. Il se voit récompensé par des concessions exorbitantes, des quartiers urbains et même des villes entières, que les républiques maritimes italiennes auraient été bien incapables de tenir avec une poigné d'hommes. Les Génois à Antioche dès 1098, dans le royaume de Jérusalem avec le grand diplôme de 1104, les Vénitiens avec le pactum Warmundi de 1123 sont mieux servis que les Pisans qui n'obtiennent qu'une charte de Tancrede en 1108 et une autre de Baudouin II, à une date proche de 1130 .

La phase de stabilisation qui s'ouvre dans les dernières années du règne de Baudouin II et les premières de son succeseur, Foulque d'Anjou, sont beaucoup moins favorable aux républiques maritimes italiennes. Souverains et princes francs cherchent à reprendre en temps de paix ce qu'ils avaient concédé au moment des combats. De 1130 a 1153, on ne rencontre que deux privileges émanant de Raymond de Poitiers, dont la principauté d'Antioche se trouve menacée par la reconquête byzantine. En confirmant des chartes antérieures, le prince cherche à resserrer ses liens avec les communes italiennes. Après 1150, les textes de concessions se trouvent groupés en deux brèves périodes, où les souverains manifestent une générosité intéressée: de 1153 a 1157 , moment où Nâr-al-Dîn attaque la principauté d'Antioche, de 1167 a 1169, en liaison avec les campagnes d'Egypte. Ayant besoin du concours des Occidentaux, le roi Amaury cherche a se l'assurer en confirmant ou en élargissant les chartes antérieures.

En dehors de ces quelques textes, les souverains et les princes francs cherchent plutôt, avant le années 1180 , à restaurer l'intégralité de leur pouvoir, diminué par les exemptions et prérogatives dont jouissent les Italiens. Deux incidents le montrent. Le premier a trait à l'épitaphe en lettres d'or que les Génois ont fait placer en 1105 dans le choeur du SaintSépulcre, pour rappeler aux générations futures la teneur des concessions que Baudouin Ier venait de leur accorder ${ }^{22}$. Or, pendant le règne d'Amaury, les chanoines du Saint-Sépulcre déposent l'inscription, sans doute à l'instigation du roi. Gênes s'adresse à la papauté pour la défense de ses droits; rien n'y fait. Il faut attendre 1192 pour que Conrad de Montferrat,

${ }^{22}$ KEDAR, I Comuni iraliani, p. 320. 
soutenu par les génois dans ses prêtentions au trône royal, confirme les privilèges de ses alliés et les autorise à restaurer la célebre inscription ${ }^{23}$. Le second a pour victimes les Pisans. Les rois de Jérusalem veulent leur imposer la distinction entre les résidents et les non-résidents, afin de limiter à ces derniers les droits d'exterritorialité et de soumettre tous les autres à la loi commune du royaume. Les comtes de Tripoli prennent prétexte d'actes de piraterie pour restreindre les droits des Pisans dans leur comté $e^{24}$. Seule Venise semble avoir échappé à cette reprise en main menée par les souverains. Le gouvernement ducal n'en prend pas moins soin de faire confirmer par le Saint Siege en 1165 puis en 1200 les privileges dont jouissent ses ressortissants en Terre Sainte ${ }^{25}$.

A cette date, d'ailleurs, le pouvoir royal a sombré devant les exigences des Communes. A partir de 1186, les princes francs, dont le territoire est menace par les forces de Saladin, sont a nouveau contraints de recourir aux services des Italiens. Ils ne peuvent plus abolir leurs privilèges, mais se voient obligés de les confïrmer, voire même de les élargir. De 1186 à 1195, les diplômes se succèdent, davantage en faveur des Génois et des Vénitiens que des Pisans ${ }^{26}$. Ils promettent de larges concessions dans les villes à reconquérir, Ascalon, Jérusalem, Jaffa et surtout Acre. Aussi, apres la rendition de cette ville en juillet 1191, les communes italiennes jouent des rivalités entre Guy de Lusignan et Conrad de Montferrat pour accroître leurs droits dans le nouveau royaume et les renforcer a Antioche et a Tripoli.

Confortées dans leurs privileges, les communes italiennes ont tendance à la fin du XII' siècle, à devenir un Etat dans l'Etat. Mieux même, non contents de leurs exemptions et de leurs droits d'exterritorialité, leurs membres s'ingénient à acquérir des fiefs et des seigneuries à la faveur d'heureuses transactions ou successions, et a revendiquer sur ces terres les

\footnotetext{
${ }^{23}$ KeDAR, I Comuni Italiani, pp. 332-333; FAVREAU-LILE, Die Italiener, ad indicem Genua.

${ }^{24}$ FAVREAU-LIUE, Die Italiener, Pp. 187-205; EADEM, Die Italienische Levante-Piraterie und die Sicherheit der Seewege nach Syrien im 12 und 13 Jahrhundern, in "Vierteljahrachrift für Sozial und Wirtschaftsgeschichte, 65/4 (1978), pp. 494-495; J. PRAWER, The Italians, Pp. 241-247.

${ }^{25}$ TAFEL-THOMAS, Urkunden, I, pp. 145-146, 281-286.

${ }^{20}$ R. ROHRICHT, Regesta regni hierosolymitani 1097-1291, (2 vol., Innsbrück, 1893-1904; New York2, Burt Franklin, s.d.); nn 659 et sq; voir FAVREAU-LIUE, Die ltaliener, pp. 230236; PRAWER, Colonialismo medievale, Pp. 118-119.
} 
mêmes exemptions qu'à l'intérieur des quartiers urbains accordés aux communes. En vain, princes et souverains cherchent-ils à les contraindre de choisir entre les privileges dérivant de leur nationalité ou le paiement des taxes royales sur leurs nouvelles propriétés: un choix qu'au cours du XIII siecle la couronne de Jérusalem ne réussit pas réellement à imposer. Les graves différends entre le pouvoir royal et les communes et entre celles-ci

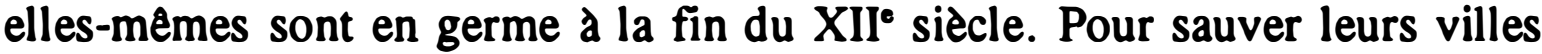
de la reconquête sarrasine, princes et rois les ont presque aliénées d'avance aux républiques maritimes italiennes. La guerre a rompu l'équilibre qu'ils s'étaient efforcé de restaurer dans les années 1150 .

Il n'y a pas lieu d'entrer dans le détail des diplômes obtenus au cours du XIII' siècle par les diverses républiques maritimes, ni de reprendre le récit des luttes sanglantes qui les ont opposées en Terre Sainte. En ce qui concerne les chartes, elles se distinguent des précédentes par leur caractere tres pointilliste et tres particulariste. Il n'y a plus de concession générale pour l'ensemble du royaume de Jérusalem, mais des privilèges concernant une seule ville. Par exemple, les Génois obtiennent des faveurs a Tripoli en 1203, a Beyrouth en 1221, 1223 et 1233, à Haïfa en 1234, à Tyr en 1264 et, pour la Syrie du Nord, a Antioche en 1199 et $1216^{27}$. Sans doute sur la requête des bénéficiaires, les clauses se font très minutieuses: la liberté pour les hommes, les navires, les marchandises, exemption des taxes pesant sur le trafic maritime, description précise des concessions territoriales, engagements politiques des parties contractantes, tout est soigneusement pesé et nettement consigné dans l'acte.

L'affaiblissement du pouvoir royal, le transfert du titre à un souverain étranger au royaume et, en corollaire, la montée des ambitions baronniales laisent libre cours aux rivalités des communes italiennes. Elles débutent avec les séquelles de la IVe croissade, lorsque Gênes donne son appui a Henri comte de Malte qui s'empare en 1205 du chateau de Nefin, en rebellion contre le comte de Tripoli ${ }^{28}$. Elles se poursuivent a Acre par incessants conflits à propos des limites fixées aux comptoirs des communes; en 1222, les Pisans détruisent la tour des Génois a Acre ${ }^{29}$. Dans la lutte

\footnotetext{
${ }^{27}$ PISTARINO, I Comuni italiani, pp. 121-126.

${ }^{28}$ Marie-Luise FAVreAU, Graf Heinrich von Malta, Genua und Boernund IV von Antiochia. Eine Urkundenkritische Studie, in "Quellen und Forschungen...", 58 (1978), pp. 181-215.

${ }^{29}$ Marie-Luise FAVREAU-LIUE, Friedenssicherung und Komfliksbegrenzung: Genua, Pisa und Venedig in Akkon, ca. 1200-1224, in "I Comuni italiani", pp. 429-447.
} 
qui oppose Frédéric II et son lieutenant Riccardo Filangieri au clan baronnial mené par les Ibelins, Gênes est favorable à ceux-ci tandis que Pise, gibeline, prend parti pour les Impériaux ${ }^{30}$. Les passions du séjour de Saint Louis à Acre se réveillent brutalement avec la guerre dite de Saint-Sabas qui oppose Pisans, Vénitiens, Templiers, Teutoniques et Marsellais d'une part, aux Génois, soutenus par les Hospitaliers et les marchands d'Ancône et de Catalogne, d'autre part. A l'issue de ces violents affrontements, les Gênois vaincus abandonnent leur quartier d'Acre, partiellement annexé par les Pisans, et vont se réfugiers à $\mathrm{Tyr}^{31}$. Ils trouvent leur revanche en s'aIliant avec l'empereur de Nicée, Michel VIII Paléologue, et en contribuant, par le traité de Nymphée, à la perte de l'empire latin de Constantinople, dominé par Venise $\mathrm{e}^{32}$.

Malgrés les interventions constantes du Saint-Siège, les communes italiennes continuent à rivaliser après 1261 pour ruiner les Etats francs de Syrie-Palestine. Les Génois, soutenus par le seigneur de Tyr, Philippe de Montfort, cherchent à retrouver leurs possessions a Acre. Ils y reviennent en imposant leurs conditions aux Pisans, vaincus a la bataille de la Meloria (1284). De leur côté les Vénitiens se rapprochent de Charles Ier d'Anjou et dénoncent auprès du sultan mamelak l'ingérence génoise dans les affaires de Tripoli. En 1287, en effet, les habitants de cette ville, a la mort de leur prince Bohémond VII, font appel à l'amiral génois Bendetto Zaccaria, pour soutenir leur commune naissante. Inquiete des conséquences pour son commerce avec l'Egypte, Gênes est contrainte de désavouer son représen$\operatorname{tant}^{33}$. Ainsi a la veille de la disparition des Etats francs de Syrie-Palestine, les républiques maritimes italiennes, attachées à leurs intérêts propres,

\footnotetext{
${ }^{30}$ David JACOISY, The Kingdoin of Jerusalein and the collapse of Hohenstaufen power in the Levant, in "Dumbarton Oaks Papers", 40 (1986), pp. 83-101.

31 Joshua Prawi:k, Histoire du royaume latin de Jérusaleın, (2 vol., Paris, Éditions du CNRS, 1969-1970), II, pp. 359-373; G. CARO, Genova e la supremazia sul Mediterraneo (1257-1311), (2 vol., Genova, Atti della Societa ligure di Storia patria vol. XIV-XV, 1974 1975), I, pp. 36-49. Sur les marchands d'Ancóne, voir D. ABULAFA, The Anconilan privileges in the Latin Kingdoin of Jerusalein and the Levant Trade of Ancona, in "I Comuni italiani", pp. 523-570.

${ }^{32}$ Camillo MANFronI, Le relazioni fra Genova, l'impero bizantino e $i$ Turchi, in "Alti della Società ligure", 28 (1898), pp. 656-666; G. CARO, Genova e la supremazia, I, pp. 100113; Donald J. GliANNKOPLOS, Einperor Michael Palaeologus and the West 1258-1282, Cambridge (Mass.), 1959, pp. 81-91; Michel BALARD, La Romanie génoise XXI-début du XV siecle), (2 vol., Rome-Génes, BEFAR 235, 1978), I, pp. $42-45$. 536.

${ }^{33}$ G. CARO, Genova e la supremazia, II, pp. 119-131; J. PRAWER, Histoire, II, pp. 532 -
} 
sont incapables de concevoir une politique unie pour préserver leurs positions en Terre Sainte. Au contraire, leurs rivalités ont pour beaucop contribué à la désagrégation rapide de la Syrie franque dans la seconde moitié du XIII siecle.

\section{LA LOCALISATION DES COMPTOIRS ITALIENS EN SYRIE-PALESTINE}

L'analyse des conditions d'établissement des Italiens en Syrie-Palestine et de leur role politique dans les Etats francs doit maintenant conduire à l'étude même des concessions obtenues par les diverses républiques maritimes. Où celles-ci détenaient-elles les privilèges les plus importants?

Le premier des Etats francs crés, le comté d'Edesse, n'intéresse pas les hommes d'affaires italiens. Aucune charte en leur favor n'en émane. Sans débouché sur la mer, peuplé d'un nombre infime d'Occidentaux, le comté n'attire guère les marchands ${ }^{34}$. Pour remplir leur rôle d'intermédiaires entre la Terre Sainte et l'Occident, ceux-ci ont besoin de bases maritimes sûres où faire relâcher leurs navires. Pour les mêmes raisons, les villes de l'intérieur des Etats francs ont peu d'attrait pour les Italiens, si l'on excepte Jérusalem et le pèlerinage aux Lieux Saints. Mais très peu s'y installent: le cartulaire du Saint Sépulcre ne cite qu'une demi-douzaine d'Italiens, dont un seul ressortissant certain des républiques maritimes ${ }^{35}$. Dans les petits centres de l'intérieur, tels Tibériade ou Naplouse, les marchés limités à quelques productions agricoles n'intéressent en rien nos hommes d'affaires.

Est-ce à dire qu'on les rencontre dans toutes les villes de la côte? La question revient a celle, plus complexe, de la réalité des avantages consentis aux communes italiennes. Il ne suffit pas que Baudouin Ier ait autorisé les Génois à s'établir à Jaffa, Arsuf ou Césarée ou que son sucesseur ait accordé aux Vénitiens des privilèges à Sidon pour que ces petits

\footnotetext{
"Monique AmourouX-Mourad, Le Cornté d'Edesse 1098-1150, Paris, Geuthner, 1988, pp. 135.

${ }^{35}$ Geneviève BRESC-BAUTTER, Le cartulaire du chapitre du Saint-Sépulcre de Jérusalem, Paris, Documents relatifs à l'histoire des croisades publiés par l'Académie des Inscriptions et Belles-Lettres, 1984, pp. 238-240.
} 
centres voient se développer une colonie italienne $e^{36}$. Les infrastructures portuaires y sont trop sommaires, les réseaux de relations trop étriqués, pour qu'ils s'éveillent à une vie économique intense. Les hommes d'affaires ont besoin de hâvres sûrs pour leurs vaisseaux, de logements et d'entrepôts au sein d'une collectivité active, de liaisons faciles avec l'arrière-pays caravanier. Seuls les ports de quelque importance offrent ces avantages: Acre, Tyr et Beyrouth dans le royaume de Jérusalem, Tripoli et Laodicée plus au nord, villes auxquelles s'adjoint Antioche, capitale de principauté, reliee par l'Oronte à Port Saint-Syméon ${ }^{37}$.

Ce sont là les principaux établissements occupés aux $\mathrm{XII}^{\circ}$ et $\mathrm{XIII}^{\circ}$ siècles par les Italiens, en même temps que deux seigneuries, Gibelet aux mains de la famille génoise des Embriaci et Botron, possessions du pisan Plebanus.

Mais au long des deux siècles de leur présence en Syrie-Palestine, les interêts des diverses communes ne sont pas identiques, de la principauté d'Antioche au royaume de Jérusalem. Les Génois s'installent les premiers à Antioche, des 1098; ils sont suivis par les Vénitiens et dix ans plus tard par les Pisans. Mais ils n'y obtiennent une curia, avec pleine juridiction sur leurs concitoyens, qu'en $1189^{38}$, tandis que les Pisans doivent attendre 1216 pour bénéficier du même avantage. Dans le comté de Tripoli, les Vénitiens sont en 1100 les premiers privilégiés, mais ne s'y maintiennent pas. Le Génois en 1109 reçoivent en toute propriêté Gibelet, qu'ils concèdent à l'illustre famille des Embriaci, et le tiers de Tripoli, qu'ils ne conservent pas. Ce n'est qu'en 1203 que Bohémond IV leur reconnaît le droit d'y posséder quelques maisons, une curia et pleine liberté de commerce ${ }^{39}$. Les Pisans doivent attendre le règne de Raymond III pour obtenir un quar-

\footnotetext{
${ }^{36}$ La présence des Génois a Césarte en novembre 1220 est davantage un fait militaire que le témoignage d'une activité commerciale; J. PRAWER, Histoire du royaume latin, II, p. 163.

37J. PraWER, Colonialismo, p. 145; M.L. FAVREAU-LIUE, Die Italiener, pp. 497-528.

${ }^{38} \mathrm{C}$. CAHEN, La Syrie du nord d l'époque des croisades et la principauté franque d'Antioche, Paris, Geuthner, 1940, pp. 490-500; M.L. FAVREAU-LIUE, Die Italiener, pp. 486-493; G. PISTARINo, I Comuni iraliani, p. 104.

${ }^{39}$ E.H. BYRNE, The Genoese colonies in Syria, in "The Crusades and other historical Essays presented to Dana C. Munro", New-York, 1928, pp. 139-152; Jean RICHARD, Le Comie de Tripoli sous la dynastie toulousaine, Paris, Geuthner, 1945, pp. 84-85; M.L. FAVREU-LIUE, Die Italiener, pp. 483-486; Pasquale LISCIANDREIU, Trattati e negoziazioni politiche della Repubblica di Genova (958-1797), Genova, Atti della Societa ligure di Storia patria, 1960, p. 41.
} 
tier a Tripoli, que leur brouille avec Bohémond IV leur fait perdre et qu'ils ne retrouvent qu'en $1233^{40}$.

Reste le royaume de Jérusalem, où les positions des trois républiques sont plus mélangées. Les Vénitiens défendent leurs droits sur le tiers de la ville de Tyr, que leur confisque en 1258 Philippe de Montfort, allié des Génois, au moment de la guerre de Saint-Sabas. A Acre, leurs possessions remonteraient à l'anné 1110; elles constituent le noyau primitif de leur quartier, agrandi en 1123 par les pactum Warmundi et dont l'inventaire dressé en 1244 par Marsilio Zorzi donne' une description précise ${ }^{41}$. L'établissement des Génois à Acre date du diplome que leur concede Baudouin Ier en 1104; il se développe à l'écart du rivage, dont le sépare le quartier de la Chaîne. Pas moins de huit chartes au cours du XII' siecle ont trait à ce quartier, dont tour à tour Guy de Lusignan, Conrad de Montferrat et Henri de Champagne confirment la possession aux Génois entre 1186 et 1195. Un inventaire du 14 juillet 1249 donne la liste des biens et des revenus de la Commune à Acre, quelques années avant que les Génois ne soient contraints de quitter leur quartier, a la suite de la guerre de Saint-Sabas ${ }^{42}$. Ils ne le retrouvent que dans les annees qui précedent la disparition du royaume latin. En revanche, après 1258 se développe le rôle de leur colonie de Tyr, connue elle aussi grâce à un inventaire détaillé du 3 mai $1250^{43}$. Quant aux Pisans, leurs interêts se concentrent d'abord à Tyr, où Baudouin II leur accorde cing maisons en 1130. Ils n'apparaissent à Acre qu'en 1168, en obtenant du roi Amury un petit quartier dans le sud de la ville, agrandi en 1187 et 1189 par Conrad de Montferrat et Guy de Lusignan, et une nouvelle fois après 1258 grâce à l'annexion d'une partie du quartier génois ${ }^{44}$. Bref, dans le royaume de Jérusalem, seuls Tyr, Acre et

\footnotetext{
${ }^{40}$ R. ROHRICHT, Regesta, pp. 155, 164, 176; G. MOUER, Documenti sulle relazioni delle cittd toscane coll'Oriente cristiano, Firenze, 1879, n' 68, p. 99.

4lJ. PRAWER, The Italians, pp. 229-237; David JACOBY, Crusader Acre in the 13th century: urban layout and topography, in "Studies on the Crusader States and on Venetian Expansion", Londres, Variorum Reprints, 1989, étude V; IDEM, L'expansion occidentale dans le Levant: les Vénitiens a Acre dans la seconde moitié du XIIP siecle, in "Joumal of Medieval History", 3 (1977), pp. 225-264.

42J. PRAWER, The Italians, pp. 237-241; D. JACOBY, Studies, V; G. PISTARINO, I Comuni italiani, Pp. 119-120.

${ }^{43}$ Comelio DesimonI, Quatre titres des propriétés des Génois d Acre et d Tyr, in "Archives de l'Orient latin", 2 (1884), pp. 213-230.

${ }^{\omega_{R}}$. ROHRICHT, Regesla, pp. 117, 163, 178, 182, 191; voir D. JACOBY, Studies, V.
} 
Beyrouth comptent vraiment pour les Communes italiennes. En revanche, Jaffa, Arsuf, Sidon et Césarée, citées dans les diplômes des premiers temps de la conquête, disparaissent pratiquement des textes postérieurs, sauf dans des chartes de confirmation $-1186,1192$ pour les Génois, 1229 pour les Pisans- sans doute par l'effet d'une répétition mécanique des clauses inscrites dans les textes du début du XII ${ }^{e}$ siecle. Les situations diverses que connaissent dans les Etats francs les trois républiques maritimes italiennes ressortent des circonstances, mais aussi de la politique méditerranéenne que mêne chacune d'entre elles. La Syrie-Palestine ne représente en effet qu'un domaine d'expansion possible, à coté de l'empire byzantin et de l'Egypte. Selon ses intérêts propres ici et là, chaque république maritime intervient plus ou moins dans la politique des Etats francs et en reçoit donc des avantages assez différents. Déterminer leur nature précise permettra de mieux saisir dans quelles conditions s'exerce l'activité commerciale des hommes d'affaires italiens.

\section{LES PRIVILĖGES ACCORDÉS AUX ITALIENS: LEUR NATURE}

Marchands avant tout, les ressortissants des républiques maritimes cherchent essentiellement à obtenir des avantages qui puissent faciliter la bonne marche de leurs affaires. Une première catégorie de droite porte sur l'exemption des taxes sur les transactions et des droits de douane, regroupés sous le terme de comerchium, par lequel on désignait cet ensemble de taxes commerciales dan le monde byzantin ${ }^{45}$. A cet égard, le traitement dont font l'objet les trois communes n'est pas exactement identique. Gênes attache la plus grande importance a ce type d'exemptions, toujours citée dans les diplômes qu'elle obtient dans les Etats francs: avec trente-cinq mentions au cours du XII ${ }^{\circ}$ siecle, ce droit vient largement en tête de toutes les concessions et figure souvent en première place dans le texte des chartes. Les Vénitiens s'en préoccupent tout autant, mais n'obtiennent pas partout, comme leurs rivaux, une exemption totale. Dans le royaume de Jérusalem, en effet, le pactum Warmundi (1123) et la charte de Baudouin II

\footnotetext{
${ }^{45}$ Helene ANTONIADIs-BiBicou, Recherches sur les douanes à Byzance, Paris, Ammand Colin, 1963, pp. 107-108.
} 
de 1125 exceptent du bénéfice de l'exemption les navires vénitiens chargés de pelerins ${ }^{46}$. Dans la principauté d'Antioche, les sujets de la Sérénissime continuent a payer des droits jusqu'a la fin du XII ${ }^{\circ}$ siecle, au taux de 4 a 5 $\%$ en 1153 , réduit de moitié en 1167 , et fixé finalement à $1 \%$ en $1183^{47}$. Quant aux Pisans, après avoir joui dans cette même principauté d'une exemption totale du comerchium en 1108, ils sont astreints en 1154 a payer la moitié des droits ${ }^{48}$ : recul significatif qui marque le souci de Renaud de Châtillon et de son épouse Constance de retrouver quelques sources de revenus. En revanche, dans le comte de Tripoli et dans le royaume de Jérusalem, l'exemption est totale, mais elle n'intervient qu'au moment de la IIIe Croisade; elle est renouvelée par Frédéric II en 1229 pour le royaume et par Bohémond $V$ en 1233 pour Tripoli. L'application n'en est pas aisée: comment distinguer en effet une marchandise ou un homme d'affaires privilégié de ceux qui ne doivent pas l'être? Les représentants des communes sont bien souvent requis pour attester de la citoyenneté des exemptés auprès des officiers de la douane.

On s'est intorrogé sur les effets pervers de si larges concessions ${ }^{49}$. Les souverains ne seraint-ils pas allés à l'encontre de leurs intérêts à long terme en accordant de tels privileges commerciaux?

En fait, les exemptions dont bénéficient les marchands italiens ne sont pas totales. Certains doivent une partie des taxes de la "chaîne" aux officiers portuaires; a peu pres tous sont soumis au paiement pour les marchandises apportées ou emportées des ou vers les pays musulmans. Sur les marchés locaux, les denrées sont pesées par des mensuratores et assujetties a des taxes ad valorem levées par les officiers de la fonde; a Tyr échappe a leur compétence et a leur juridiction le marché de la viande, du savon, des poissons, des produits tinctoriaux et de la tannerie; à Acre, le marché de la viande et de la tannerie. Les Italiens bénéficient rarement d'une exemption totale des droits -qui a Acre vont de $41 / 6 \%$ a $25 \%$ selon les marchandi-

\footnotetext{
${ }^{40}$ M. Pozza, Venezia e il regno, pp. 375 et 381; M.L. FAVREAU-LIUE, Die Italiener, pp. 489-493.

${ }^{47}$ G.L.F. TAFEL-G.M. Thomas, Urkunden, I, Pp. 175-176; M.L. FAVREAU-LIUE, Die Italiener, Pp. 489-493.

${ }^{4}$ R. ROHRICHT, Regesta, p. 74.

${ }^{49} \mathrm{Jean}$ RICHARD, Colonies marchandes privilkgiées et marché seigneurial. La fonde d'Acre, in "Le Moyen Age" (1953), Pp. 325-340; Jonathan RILEY-SMoTH, Govermment in Latin Syria and the commercial privileges of foreign merchants, in D. Bukor 6d., "Relations between East and Weat in the Middlo Ager", Edinburgh, Univornity Prese, 1973, Pp. 109-132.
} 
ses $^{\text {so }}$ - plutot d'une exemption partielle pour certaines marchandises ou bien pour certaines opérations, vente ou achat. En outre, les autorites locales s'efforcent d'empêcher leurs ressortissants d'accéder aux marchés privilégiés des Italiens distincts des fondes ou marchés royaux et seigneuriaux. Dans ces conditions, on peut estimer que les privileges accordés aux marchands occidentaux provoquent un accroissement des affaires tel qu'ils compensent le manque à gagner des souverains et des seigneurs locaux.

Ceux-ci abandonnent en faveur des communes italiennes leurs droits sur les epaves et sur les biens des marchands morts intestats; ils garantissent aussi la sécurité personnelle des négociants. Dans leurs quartiers de Syrie-Palestine, les Italiens sont intéressés par un autre avantage: pouvoir utiliser leurs propres poids et mesures, et non ceux des pouvoirs locaux qui par l'intermédiaire des mensuratores perçoivent une taxe pour cet usage. Dès 1123, ce droit est acquis aux Vénitiens dans le royaume de Jérusalem et à Acre en particulier, sauf lorsqu'ils achètent des marchandises a des tiers. Les Génois et les Pisans profitent plus tard du même avantage: les premiers à Tyr en 1190, les seconds en 1187 dans cette meme ville ${ }^{31}$.

Quelques concessions financières completent cet abandon de ressources, consenti par les autorités locales. Venise benéficie d'un revenu annuel de 300 besants levés sur la fonde de Tyr, puis sur les profits de la chaîne d'Acre ${ }^{52}$. En 1104, Baudouin Ier accorde aux Génois 300 besants et le tiers des revenus du port d'Acre; mais cette seconde concession n'a sans doute jamais reçu pleine exécution, bien que, sous les contraintes de la guerre, elle ait été renouvelée par Conrad de Montferrat en 1190 pour Tyr, en 1192 pour Acre $^{53}$. De même, les Pisans, au moment de la IIle croisa-

"Assises des Bourgeois de JÉrusalem, in "Recueil des Historiens des Croisades. Lois", II, pp. 171-172.

'1M. PozzA, Venezia, pp. 375-381; Cesare IMPERIALE dI SANT-ANGELO, Codice diplomatico della Repubblica di Genova, (3 vol., Roma, Istituto storico per il Medioevo, 1936-1942), II, p. 370; R. RÖHRICHT, Regesta, p. 177.

${ }^{2}$ G.L.F. TAFEL-G.M. THOMAS, Urikenden, I, Pp. 141 et 168; M. POZZA, Venezia, p. 376; M.L. FAVREAU-LIUE, Die Italiener, p. 464.

${ }^{33}$ C. IMPERIALE, Codice diplomatico, I, pp. 18, 21; II, p. 371; III, p. 49. 
de, se voient promettre une somme de 2000 besants par an sur les revenus de la fonde et de la chaîne d'Acrest.

Les concessions foncières servent d'assise aux communautés marchandes italiennes. Elles prennent au cours du XII ${ }^{\circ}$ siècle de plus en plus d'importance; d'abord -c'est le cas à Antioche en 1098 en faveur des Génois- quelques maisons, puis des quartiers entiers passent aux mains des communes italiennes: une ruga, mot qui désigne plus un ilot urbain qu'une simple rue ${ }^{55}$, parfois le tiers d'une ville et exceptionnellement la totalité d'une place à conquérir. Comme l'a remarqué J. Prawer, de tels privilegees s'ils avaient été utilisés à la lettre, n'auraient laissé aucune cité du royaume au pouvoir du roi et de ses vassaux ${ }^{36}$. En fait, les seuls quartiers réellement utilisés par les marchands italiens demeurent ceux des grands ports, Acre, Tyr, Beyrouth, Tripoli et Laodiceee, et de la capitale de la principaute du nord, Antioche.

Dans ces quartiers, les ressortissants des républiques maritimes cherchent a obtenir tout ce qui est indispensable a leur vie quotidienne: une église, un entrepot ou fondouk, une place, un palais, un four, un moulin, un abattoir, des bains. La concession d'une église, assortie ou non du jus parrochiale et du patronage de l'église métropolitaine, donne lieu à de longs différends avec les autorités ecclésiastiques de Terre Sainte ${ }^{57}$. Les espaces nécessaires a l'activité commerciale -entrepôts pour les marchandises, logements pour les marchands de passage, demeures des gardiensforment un fondouk. La premiere mention remonte a 1098, avec la charte de Bohémond en faveur des Génois ${ }^{58}$. Chacun des quartiers concédés aux Italiens dans les villes cotières devait disposer de quelque infrastructure commerciale; les expressions interaruga et vicus Venetorum le sous-entendent ${ }^{\text {s9 }}$. L'ensemble des batiments publics nécessaires à l'existence quotidienne d'une communauté solidement établie n'est mentionné que dans les

M. R. RHRICHT, Regesta, p. 180; M.L. FAVREAU-LIUE, Die italienischen Kirchen im Heiligen Land (1098-1291), in "Studi veneziani", 13 (1987), Pp. 15-101; EADEM, Die Italiener, passim.

SSD. JACOBY, Crusader Acre, p. 15.

SoJ. PRAWER, The Ilalians, p. 219.

${ }^{37}$ M.L. FAVREAU-LIUE, Die italienischen Kirchen im Heiligen Land (1098-1291), in "Studi veneziani", 13 (1987), pp. 15-101; EADEM, Die Italiener, passim.

STC. IMPERALL, Codice diplomatico, I, p. 11.

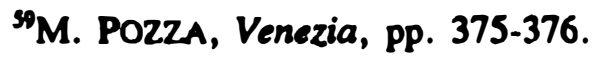


chartes de la seconde moitié du XII ${ }^{e}$ siècle pour les Génois et les Pisans, alors que, des 1123, le pactum Warmundi se préoccupe des fours, des bains et des moulins a Acre et dans les autres villes du royaume de Jérusalem. Au cours du XIII ${ }^{e}$ siècle, les inventaires vénitiens dressés par le bailli Marsiglio Zorzi (1243-1244) et génois rédigés par Guglielmo di Bulgaro et Simeno Malocello (1249) énumerent à Acre tout un ensemble de batiments, de murs, de palais et de fortifications, prouvant qu'à cette date les communes italiennes ont conçu leurs établissements en terme de colonie permanente et pleinement autonome ${ }^{60}$. Elles disposent alors de tous les édifices nécessaires à la vie sociale et économique d'une communauté établie à demeure et qui cherche à échapper à toute dépendance extérieure.

Complétant ces édifices urbains, les communes italiennes ont également acquis des dépendances extérieures, terres, jardins, villages ou casaux hors des enceintes fortifiées. Des 1123, le pactum Warmundi accorde aux Vénitiens le tiers des possessions extérieures de la ville de $\mathrm{Tyr}^{61}$. Les Génois disposent de casaux à Arsuf et Césarée, de terres à Gibelet et de vastes propriétés au nord-est d'Acre, que la découverte récente de trois bornes portant le nom IANVA permet de mieux situer ${ }^{62}$. Les biens ruraux les mieux connus sont ceux des Pisans qui reçoivent cinq charruées a Tyr en 1157 , des jardins à Jaffa et à Acre en 1187, et surtout des casaux précisément nommés, près de Tyr et de Jaffa en 1187, près d'Acre en 1187 et $1188^{63}$. Il y a là tout un ensemble de possessions foncières, destinées sans nul doute à pourvoir au ravitaillement des communautés italiennes. Il va de soi que ce ne sont pas les colons qui les cultivent eux-mêmes: ils les accensent à des bourgeois ou à des indigènes dont les inventaires du XIII ${ }^{\circ}$ siecle passent malheureusement les noms sous silence. Pour les communes italiennes, la terre est en Syrie-Palestine une source de revenus secondaire, alors qu'elle est primordiale pour les Francs qui y sont établis.

\footnotetext{
${ }^{60}$ G.L.F. TAFEL-G.M. THOMAS, Urkunden, II, pp. 390-397; C. DESIMONI, Quatre titres. Pour la description détaillée de ces colonies italiennes d'Acre, voir J. PRAWER, The ltalians, et D. JACOBY, Crusader Acre et $L$ 'expansion occidentale.

${ }^{61}$ M. Pozza, Venezia, p. 375; M.L. Favreau-Liue, Die Italiener, pp. 424-435.

${ }^{62}$ Rafael FRANKEL, I cippi confinari genovesi del kibbutz Shomrat, in "I Comuni italiani", Pp. 691-695. 426-427.

${ }^{63}$ R. ROHRICHT, Regesta, pp. 177, 178, 180; M.L. FAVREAU-LIIIE, Die ltaliener, pp.
} 


\section{MARCHANDS ITALIENS ET COLONS}

L'activité commerciale est bien la raison d'être des colonies italiennes de Syrie-Palestine. Elle s'exerce par la coopération intime des résidents permanents et des marchands de passage. Au début du XII ${ }^{e}$ siècle, les premiers n'étaient qu'une poignée: quelques hommes laissés par les autorités de la métropole pour occuper les lieux concédés, nouer les contacts avec les indigenes, préparer le séjour des marchands du passagium annue' "hivernant" en Syrie-Palestine d'octobre ou de novembre à mars. Peu a peu, à partir du milieu du XII ${ }^{\circ}$ siècle des visiteurs occasionnels s'établissent en Terre Sainte. Des familles entieres prennent racine: rameaux des clans familiaux de la métropole, facteurs des grandes sociétés actives dans le commerce du Levant, marins ou artisans en quête d'aventure ou de fortune. Joshua Prawer a mis en évidence les représentants de l'artistocratie vénitienne établis en Terre Sainte: Rolando Contarini, Domenico Acontano, Jacopo Dandolo, les familles Dulce, Morosini et Falieri, bénéficiaires des inféodations effectuées par la Commune, officiers vénitiens se fixant en Orient apres leur sortie de charge ${ }^{64}$.

Au cours du XIII' siecle, la communauté d'Acre comprend de nombreux membres des case vecchie et nuove de Venise (Querini, Venier, Vassano) mais aussi de nombreux popolani comme les Boninsegna, Benedetto, Cavalotto, Zovene, Brizi, Marmora et Barisan, sans compter des étrangers latins et des autochtones qui ont pu bénéficier du statut de Vénitiens. On retrouve à Famagouste dans la dernière décennie du XIII' siècle un certain nombre de représenants de ces familles réfugiées de Terre Sainte. Au total, peur-être un millier d'hommes, réduits à trois ou quatre centaines par les flux des dêparts avant $1291^{65}$.

Du côte génois, le cas des Embriaci, famille d'origine vicomtale qui fait souche en Orient, est exemplaire. Guglielmo II, petit-fils du concessionnaire de Gibelet, est à l'origine de trois branches des Embriaci de Syrie, dont celle des seigneurs de Besmedin. Ils s'allient aux grandes fami508.

GH. PraWtir, The Italians, pp. 226-228; M.L. FAVreaU-LIUE, Die Italiener, pp. 498 -

${ }^{65} \mathrm{D}$. JACOBY, L'expansion, pp. 238-248; IDEM, The rise of a new emporium in the Eastern Medieterranean: Famagusta in the late thirteenth century, in "Studies on the Crusader States", étude VIII. 
lles latines et forment l'un des plus puissants baronages de Terre Sainte ${ }^{66}$. Les contrats notariaux du XII ${ }^{e}$ siecle mentionnent un certain Bonvassalo d'Antioche, un Giovanni Andrea de Tripoli, un Giovanni d'Acre, tous d'origine génoise, mais sur lesquels on ne sait pratiquement rien, de même que sur l'entourage génois et piémontais de Conrad de Montferrat ${ }^{67}$. Au cours du XIII' siecle, les colonies génoises d'Acre et de Tripoli s'accroissent de nombreux résidents permanents, dont certains, échappés à la conquête musulmane, trouvent refuge à Famagouste à partir de $1265^{68}$.

Parmi les Pisans qui se fixent en Terre Sainte au XII ${ }^{e}$ siècle, une trentaine de noms sont connus: Lambertus de Ioppen possede un bain et un four à Jaffa en 1187, Guido Pisanus des maisons à Tyr à la même date. A Tripoli, une dizaine de Pisans apparaissent dans les documents entre 1179 et 1184. Lors de la troisième Croisade, deux Pisans, Jacobus de Jhota et Waleranus de Casanova, avancent des fonds aux croisés anglais et français. Le plus célebre des expatriés est sans conteste Plebanus qui achète la main de l'héritière de la seigneurie de Botron et devient vassal du comte de Tripoli ${ }^{69}$. Au cours du XIII ${ }^{\circ}$ siecle, la colonie pisane d'Acre se grossit elle aussi de nombreux éléments venus de Pise ou de Toscane, dont on retrouve les survivants à Famagouste dans les années $1290^{70}$.

Personnalités célebres ou immigrants qu'un bref contrat notarié fait échapper à l'oubli constituent ainsi une véritable société coloniale d'outremer, qui se distingue à la fois de la noblesse franque et de la bourgeoisie latine, et qui défend aprement les intérêts commerciaux de ses co-nationaux.

\footnotetext{
${ }^{66}$ E.G. REY, Les seigneurs de Giblet, in "Revue de l'Orient latin", 3 (1895), pp. 398-422. 136.

${ }^{67}$ M.L. Favreau-Lilde, Die llaliener, pp. 509-513; G. Pistarino, I Comuni ilaliani, p.

${ }^{68} \mathrm{D}$. JACOBY, The rise, pp. 106-161; Michel BALARD, La popolazione di Famagosta all'inizio del secolo XIV, in "La storia dei Genovesi", IV, Genova, 1984, pp. $27-40$.

${ }^{60} \mathrm{C}$. OtTen-Froux, Les Pisans en Orient, I, pp. 309-313; M. TANGHERONI, Pisa e il regno crociato, pp. 513-521; M.L. FAVREAU-LILIE, Die Italiener, pp. 513-528.

${ }^{70} \mathrm{D}$. JACOBY, The rise, pp. 156-157.
} 


\section{L'ORGANISATION DES ACTIVITÉS COMMERCIALES}

Ceux-ci reposent sur des liaisons maritimes régulières et bien organisées entre l'Italie et les ports de Syrie-Palestine. A Venise, l'institution du système des mude est postérieure à la perte des Etats francs. Il n'en est pas moins vraisemblable qu'au cours du XIII siecle, s'est instauré un rythme plus ou moins régulier de transports maritimes entre la lagune vénitienne et le port d'Acre. Deux études récentes ont reconstitué le film des navigations génoises vers l'Orient aux XII' et $\mathrm{XIII}^{\circ}$ siecles ${ }^{71}$. Les routes maritimes sont dominées par les galeres pour les tâches d'accompagnament, les expéditions militaires et le chargement de quelques produits de prix, par les nefs pour les transports utiles de marchandises ou de pelerins. La stimulation apportée par les besoins de la Terre Sainte a suscité un essor sans précédent des construccions navales génoises, particulièrement à l'occasion des commandes passées par Saint Louis ${ }^{2}$. Les contrats de nolisement et divers actes notariés apportent des informations précieuses sur l'organisation de la navigation vers l'Outre-mer ${ }^{\not 3}$. Au cours des XII ${ }^{\circ}$ et XIII' siecles, les départs vers la Terre Sainte se placent à deux moments de l'annee; au printemps, ils s'échelonnent du 15 mars au 1 er mai, tout en précédant quelquefois la fin de l'hiver. Le second mouvement a lieu entre le 15 août et le 30 septembre, mais il peut exceptionnellement être différé jusqu'au 15 octobre. Quant aux retours, ils se répartissent en deux saisons: pendant l'été arrivent a Gênes les nefs parties de Syrie au cours du printemps; en novembre et décembre, celles qui ont quitté Acre à la fin de l'été et au début de l'automne, la date limite pour le départ d'Acre étant fixée au ler octobre dans l'un de nos contrats ${ }^{74}$. C'est dire que les marchands itinérants font un séjour de trois à quatre mois dans les ports syriens et que l'arrêt hivernal,

\footnotetext{
${ }^{71}$ Michel BALARD, Les transports maritimes génois vers la Terre Sainte, in "I Comuni italiani", pp. 143-174; IDEM, Le film des navigations orientales de Génes au XIIF sizcle, in Henri Dubois-Jean-Claude Hocquet-André Vauchez éd., "Horizons marins. Itinéraires spirituels", (2 vol., Paris, Publications de la Sorbonne, 1987), II, pp. 99-122.

${ }^{2}$ R. BASTARD de PÉRE, Navires méditerranéens au temps de Saint Louis, in "Revue d'histoire économique et sociale", 50 (1972), pp. 327-356; John H. PRYOR, The maval architecture of Crusader Transport Ships, in "The Mariner's Mirror", 70 (1984), pp. 171-219, 275$292,363-386$.

${ }^{73}$ Le terme Ultramare dans les actes notariés génois désigne tout ce qui est au-delà du canal d'Otrante, mais plus précisément toute la côte syrienne: cf. M. BALARD, Les transports maritimes, p. 145, note 7.

${ }^{74}$ Archives d'Etat de Genes (abrégé ASG), Notai, cart. n²7, f. 108 r (9 mars 1251).
} 
souvent limité à quelques semaines, brise le rythme de la navigation sur les routes de la Terre Sainte.

Le calendrier du mouvement des navires met en évidence le rythme bi-annuel des échanges entre Gênes et la Syrie-Palestine. Implique-t-il l'organisation de convois sur les itinéraires orientaux, donc l'intervention de la puissance publique dans la direction du trafic? Les contrats de nolisement ne mentionnent jamais l'obligation d'une navigation commune; mais le regroupement sur quelques semaines des contrats d'investissement vers l'Outre-mer, ainsi que l'obligation faite aux patrons de navire de respecter les statuts de Gênes, laissent supposer que le voyage des nefs s'effectuait en commun, au moins sur une partie du parcours: non point sous un commandement unique, mais dans le but d'une assistance mutuelle. L'obligation du convoi ne fait l'objet d'une loi qu'en $1334^{75}$

Les contrats de nolisement précisent les coûts du transport des passagers et des marchandises. Pour les premiers, une baisse relative des nolis se constate si l'on compare les tarifs demandés aux troupes de Philippe-Auguste avec les propositions faites aux envoyés de Saint Louis ${ }^{76}$. Les places de "paradis" et de château sont à bord dans un rapport de 3 à 1 avec celles de l'entrepont inférieur. Les pelerins, dont les contrats limitent toujours le nombre, doivent se contenter d'un espace réduit sur l'entrepont, à peine un mètre carré. Les marchands, eux, bénéficient de conditions de voyage un peu plus acceptables; ils se répartissent les espaces de cargaison, selon des proportions connues a l'avance, et sont admis a la table des patrons du navire. Ils exercent un contrôle sur l'armement et, en mer, sur le bon déroulement du voyage ${ }^{n}$.

Le marchand affréteur bénéficie de la gratuité du voyage pour luimême, ses serviteurs et une partie de la cargaison de Gênes vers l'Orient. Le fret -naulum- peut être acquitté au poids, ad cantaratam, ou bien le

\footnotetext{
${ }^{75}$ Giovanni FORCHER, Navi e navigazione a Genova nel Trecento. Il "Liber Gazarie", Genova, Collana storica di Fonti e Studi diretta da G. Pistarino, 1974, pp. 88-89 et 94.

${ }^{76}$ Luigi T. BelgRano, Documenti inediti riguardanti le due Crociate di San Ludovico $I X$ re di Francia, Genova, 1859, pp. 369-373, 376-377.

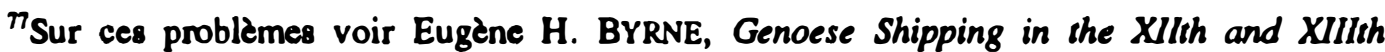
centuries, Cambridge (Mass.), 1930; Laura BAUETO, In tema di marineria genovese, in E. Ragosta éd., "Le genti del mare Mediterraneo", (2 vol., Napoli, Lucio Pironti, 1981), I, 357. 396 pp.; Hilmar-C. KRUEGER, Navi e proprietd navale a Genova. Seconda metd del secolo XII, Genova, Atti della Societa ligure di Storia patria, XXV/1, 1985.
} 
groupe d'affréteurs retient le bateau entier pour une somme donnée, ad scarsum.

Cette seconde méthode, utilisée par les envoyés de Saint-Louis en 1248 et en 1268, est beaucoup moins fréquente dans la navigation marchan$\mathrm{de}^{78}$. Selon le premier mode de calcul, les armateurs peuvent exiger la pesée des marchandises au départ et le paiement du nolis en monnaie génoise, généralement de 10 a 13 sous par cantare ${ }^{79}$. Si en revanche, les marchands s'engagent à revenir d'outre-mer sur la même bateau, et garantissent un chargement de retour proportionnel a la cargaison qu'ils emportent de Gênes, ils bénéficient alors d'une gratuité partielle sur cette derniere, mais devront payer le fret de retour sur la base de 10 a 12 besants sarracenats par cantare d'Acre (ad cantaratam Surie). Au cas où ils ne prendraient qu'en Syrie la décision de revenir sur la même navire, le nolis acquitté a Gênes leur serait déduit de la somme à payer en Syrie sur la base d'un taux de change fixé dans le contrat. Analysant ce système complexe, Byrne a remarqué à quel point il satisfait aux besoins de crédit des marchands, moins élevés en Syrie, puisqu'ils viennent de vendre leurs marchandises, qu'au départ de Gênes ${ }^{80}$. Cette méthode favorise aussi les exportations occidentales et révele peut-être un certain déséquilibre des échanges entre Gênes et la Syrie-Palestine.

La nature et la répartition dans le temps des investissements commerciaux vers la Syrie franque ne peut guère être étudiée qu'à travers le cas génois; en effet le petit nombre de contrats commerciaux vénitiens et pisans conservés n'autorise aucune conclusion ${ }^{81}$.

Dans les contrats, la variété des espèces en circulation est extrême. Ces actes sont libellés généralement en livres de Gênes, mais parfois en monnaie de Melgueil, en onces de Naples ou en besants sarracénats, la

\footnotetext{
${ }^{78}$ Un exemple: en 1291, 950 livres de nolis payés a Tedisio Doria pour l'affrùtement de deux galères vers la Syrie (ASG, notai, cart. $n^{0} 13 / 2, f$. 76 r-v).

${ }^{79}$ E.H. BYRNE, Genoese shipping, p. 52.

${ }^{80}$ E.H. BYRNE, Genoese shipping, pp. 52-58.

${ }^{81}$ Néanmoins Eliyahu ASHTOR, Il regno dei Crociati e il commercio di Levanse, in "I Comuni Italiani", pp. 30-34, dresse un tableau des investissements vénitiens aux XIle et XIIle siźcles, a partir des documents publiés par R. MOROZZO DELA ROCCA et A. LOMBNRD, Documensi del commercio veneziano nei secoli XI-XIII (Torino, 1940) et Nuovi documenti del commercio veneziano dei secoli XI-XIII (Venezia, 1953). Ces tableaux tres lacunaire n'autorisent, a notre sens, aucune conclusion de porté générale. On remarquera toutefois avec $\mathrm{Cl}$. CAHEN, Orient et Occident, p. 131, que pour les Vénitiens, Condtantinople l'emporte de loin aur l'Egypte et la Syrie-Palestine pour le nombre des contrats.
} 
monnaie d'or du royaume de Jérusalem, frappée à l'imitation du dinar, mais avec une croix et une légende chrétienne ${ }^{82}$. Les premières données sur les investissements génois proviennet du minutier de Giovanni scriba (1154-1164). Selon divers calculs effectués par Byrne, Bach et D. Abulafia ${ }^{83}$, les investissements génois dans le commerce international se répartissent à peu près également vers trois secteurs: sur 335 contrats, 116 concernent l'Italie et la Sicile, 107 la Méditerranée occidentale (Afrique du Nord, France méridionale, péninsule ibérique), 112 le bassin oriental de la Méditerranée. Parmi ces derniers, 58 ont trait à Alexandrie, 34 à la Syrie et 20 a l'empire byzantin. Le cumul des investissements aboutit a une concluison légèrement divergente: 9.031 livres prennent la direction d'Alexandrie, 10.075 livres celle de la Syrie et 2,007 livres celle de Byzance. Pour la moyenne des investissements, la Syrie arrive en tête avec 300 livres par contrat, devant Alexandrie (156 livres) et Constantinople (100 livres). Alors que l'Egypte vient en tête de liste jusqu'en 1160, un renversement s'opere alors au profit du trafic vers la Syrie-Palestine. Celui-ci est le quasi-monopole de quelques individualités et de quelques familles d'origine vicomtale qui en contrôlent les quatre cinquiemes ${ }^{84}$. A la fin du XII ${ }^{e}$ siècle, d'après l'ensemble des actes notariaux génois de 1179 à 1203, le commerce avec la Syrie absorbe autant d'investissements que le trafic avec la Sicile. Tous deux viennent largement en tête, devançant de très loin Constantinople et Alexandrie, elles-memes dépassées par Ceuta, Bougie et la Sardaigne ${ }^{85}$. D'autre part, la prédominance des gros socii stantes s'efface

\footnotetext{
"Sur les problèmes monétaires de la Syrie franque, voir J. PRAWER, Colonialisino medievale, pp. 447-456 et Cl. CAHEN, Orient et Occident, pp. 139-142 et 194-196.

"Eugene-H. BYRNE, Genoese Trade with Syria in the twelfih century, in "American Historical Review", 25 (1919-1920), pp. 191-219; Erik BACH, La cilé de Gênes au XIIE siecle, Kobenhavn, 1955, p. 50; David ABULAFA, The nuo ltalies, Cambridge, University Press, 1977, pp. 85-122. Ces calculs sont repris par J. PRAWER, Colonialismo medievale, pp. 466-467.

"Eugene-H. BYRNE, Cominercial contracts of the Genoese in the Syrian Trade of the XIIth century, in "The Quarterly Joumal of Economics", 31 (1917), pp. 128-170; Hilmar-C. KRUEGER, Genoese merchants, their partnerships and investments 1155 to 1164, in "Studi in onore di Ammando Sapori", Milano, 1957, I, 257-272; Geo PISTARINo, I Comuni italiani, pp. 71-72.

${ }^{85}$ Michel BALARD, Les Génois en Romanie entre 1204 et 1261. Recherches dans les minutiers notariaur génois, in "La mer Noire et la Romanie génoise (XIII'-XV' siècles)", London, Variorum Reprints, 1989, Étude 1, pp. 471-472.
} 
au profit d'une participation de plus en plus forte de petits marchands dans le commerce avec le Levant ${ }^{86}$.

E. Ashtor voyait le commerce italien avec l'Egypte l'emporter en volume et en valeur sur le trafic avec la Syrie jusqu'aux années $1200^{87}$. L'examen attentif des. contrats notariés conduit à anticiper au moins de deux décennies le grand élan des échanges avec le royaume de Jérusalem. Au début du XIII ${ }^{\circ}$ siècle, la zone syro-palestinienne se maintient au premier rang du commerce international génois, tant pour le nombre des contrats que pour la somme des capitaux utilisés ${ }^{88}$. De 1233 a 1259, l'Outre-mer vient constamment en tête dans les investissements génois en Méditerranée, sauf en 1256 où débute à Acre la guerre de Saint-Sabas: pendant ce quart de siècle, la part oscille entre un maximum de $71 \%$ en 1233 et un minimum de $28 \%$ en 1257; ensuite vient une reprise, $54 \%$ en 1258 et $40 \%$ en 1259 lorsque les Génois ont transféré le centre de leurs activités d'Acre à Tyr. Puis l'antagonisme vénéto-génois et les conflits entre les Mongols et les Mamelâks font chuter les investissements vers l'Outre-Mer, à partir de $1260^{89}$. Les sondages effectués par L. Balletto ${ }^{\circ 0}$ pour les deux décennies suivantes démontrent que le commerce génois avec la Syrie, tout en restant notable, particulierement en 1269 , ne retrouve jamais l'ampleur qu'il avait connue entre 1230 et 1255 . Au début des années 1280, le trafic génois avec les côtes syriennes ne vient plus qu'au quatrieme et sixième rang des destinations choisies par nos hommes d'affaires pur leurs investissements.

Meme si ce bilan statistique doit être accueilli avec une certaine prudence, en raison du nombre très variable d'une année à l'autre des contrats qui nous sont parvenus, il n'en démontre pas moins qu'un certain flux commercial se maintient entre Genes et les ports syro-palestiniens dans les années qui précèdent la conquête mamelake. Les décennies de prospérité appartiennent certes au passé, mais il est peut être excessif de dire que pour les Italiens, les ports de l'Orient latin n'ont plus d'interêt avant même qu'ils tombent sous la domination de l'Egypte, sous prétexte que d'autres

\footnotetext{
${ }^{86}$ Hilmar-C. KRUEGER, Genoese merchants, their associations and investments 1155 to 1230, in "Studi in onore di Amintore Fanfani", (3 vol., Milano, 1962), 1, pp. 415-426.

${ }^{n} \mathrm{E}$. ASHTOR, Il regno dei Crociati, p. 56.

"G. PISTaRIno, I Comuni ilaliani, p.115, d'après des calculs effectués par L. Balletto.

${ }^{90} \mathrm{M}$. BALARD, Les Génois en Romanie, pp. 489-490.

${ }^{90}$ Laura BALETTO, Fonti notarili genovesi del secondo Duecento per la storia del regno latino dei Gerusalemme, in "I Comuni italiani", pp. 175-279.
} 
ports, l'Aïas en Petite Arménie, Trébizonde, Caffa ou Tana en Mer Noire ont attiré vers eux les débouchés des grande routes transasiatiques ${ }^{91}$.

\section{LE TRAFIC}

Que pouvaient bien venir chercher ou apporter les hommes d'affaires italiens sur la côte syrienne? Leurs importations peuvent être déduites, par analogie, du chargement de la nef marseillaise, le "Saint Esprit", telle qu'il peut être établi à partir des cent cinquante contrats passés entre le 14 et le 31 mai 1248, pour la clientele du patron du navire ${ }^{2}$. On y trouve une variété étonnante de draps de Champagne, du Languedoc, de Flandre, d'Angleterre, de Bale et d'Avignon; des fils d'or de Genes et de Lucques, des futaines, des tissus de Paris et de Germanie, à côté de cargaisons de safran, d'étain, de corail, de mercure et de peaux de renard. L'exportation des textiles occidentaux est dès la fin du XII siecle un phénomene de masse. Les Francs établis en Orient sont habitués à l'usage des draps et des toiles d'Occident: la demande est donc très forte dans les villes de Terre Sainte. Le bois et le fer en pricipe interdits à l'exportation vers les pays musulmans, apparaissent peu dans les contrats; ils n'en sont pas moin attestés dans des ventes réalisées par des marchands italiens ${ }^{93}$. Quelques produits agricoles, froment, huile d'olive et safran completent avec le corail et les fourrures la large gamme des exportations occidentales ${ }^{24}$.

Celles-ci pouvaient être compensées de deux manières: soit par les productions propres du Sahil, soit par les denrées provenant du trafic caravanier.

Sur les unes et les autres, le trafic d'Acre et le manuel de Pegolotti donnent, pour des époques il est vrai différentes, d'intéressantes précisions. Le premier texte reflete les exportations du principal port syrien dans la première moitié du XIII' siècle. S'y trouvent mêlés des objets de l'artisanat local, qui devaient peu intéresser les marchands, et des produits de transit

\footnotetext{
${ }^{91}$ Cl.CAHEN, Orient et Occident, p. 203.

2J. PRAWER, Colonialismo medievale, pp. 468-469; E. ASHTOR, Il regno dei Crociati, pp.44-45.

${ }^{93} \mathrm{E}$. AshTOR, $n$ regno dei Crociati, p. 50.

${ }^{9} \mathrm{E}$. ASHTOR, Il regno dei Crociati, pp. 51-52.
} 
venus par mer d'Alexandrie ou par caravanes de la Syrie intérieure ou de l'Egypte. Les "épices" d'Orient, les parfums et les colorants (indigo, garance, bitume, balsame) voisinent avec le sucre, le lin, le coton, la soie et l'alun, sans que l'on puisse discerner l'origine géographique de ces divers produits. L'artisanat local fournit quelques denrées a l'exportation: des ouvrages de terre cuite, des tissus de coton et de soie, des camelots, des brocards, le verre de Tyr ${ }^{95}$. Le manuel de Pegolotti, qui reprend les données des derniers temps de la domination franque, insiste davantage sur la vente de diverses épices, sans qu'on puisse déterminer s'il s'agit de produits de réexportation venus d'Egypte, ou de transit, en provenance de l'Asie intérieure $^{96}$. Incontestablement, les ports syriens ont au XIII ${ }^{\circ}$ siecle une activité commerciale davantage stimulée par le transit des produits venus de la Syrie musulmane proche que par les quelques productions artisanales que les textes signalent. Achetant davantage à l'Occident qu'ils ne lui vendent, ils sont obligés de compenser leurs achats par les ressources tirées de la piété des fidèles de toute la Chrétienté.

C'est en cela que l'activité commerciale des Italiens y est fragile. Elle se développe avec un certain retard, par rapport a la conquête des croisés. Vers 1150 encore, l'Egypte paraît occuper le premier rang dans le commerce italien du Levant. La côte syro-palestinienne l'emporte à partir des années 1180: même si les évenements politiques n'ont pas toujours un impact immédiat sur l'évolution du trafic, la mutation de la fin du XII ${ }^{\circ}$ siecle peut être expliquée par les conditions moins favorables que la dynastie ayyabide fait en Egypte aux marchands italiens. La premiere moitié du XIII' siecle est l'age d'or du trafic entre les républiques maritimes et les Etats francs: Acre, Tyr, Beyrouth, Tripoli jouent alors un role de premier plan dans l'économie internationale. Mais bientôt l'invasion mongole, la conquête mamelake poussent les Italiens à rechercher des débouchés plus surs, des marchés mieux situés par rapport aux grands axes du commerce international qui ont tendance a la fin du XIII ${ }^{\circ}$ siecle à se déplacer vers le nord, vers la Petite Arménie ou les rivages de la mer Noire.

Ainsi le commerce italien en Syrie-Palestine ne doit pas son essor aux conquêtes réalisées par les Francs. Il en profite avec un retard d'un 193.

95J. Prawer, Colonialismo medievale, pp. 459-462; Cl. CAHEN, Orient et Occident, p.

${ }^{96}$ Francesco B. PEGOLOTTI, La pratica della mercatura, ed. Allan Evans, Cambridge (Mass.), The Mediaeval Academy of America, 1936, pp. 63-69. 
demi-siècle, de même que sa décrue intervient quelques trente ans avant la disparition des Etats latins. Les intérêts des hommes d'affaires ne sont pas toujours concomitants avec la situation politique des Etats auxquels ils appartiennent ou qu'ils son censés soutenir. Les ressortissants des républiques maritimes italiennes ont su utiliser d'autres terrains d'action, lorsque la côte syro-palestinienne s'est trouvée à partir des années 1260 marginalisée par rapport aux centres nerveux de l'économie internationale.

\section{BIBLIOGRAPHIE}

AbUlafia (David), The Anconitan privileges in the Latin Kingdom of Jerusalem and the Levant Trade of Ancona, in G. Airaldi-B.Z. Kedar, "I Comuni italiani nel regno crociato di Gerusalemme", Genova, Collana storica di Fonti e Studi diretta da Geo Pistarino, 1986, pp. 523-570.

AbUlafia (David), The two Italies. Economic relations between the Norman Kingdom of Sicily and the Northern Communes, Cambridge, University Press, 1977.

AIRALDI (Gabriella)-Kedar (Benjamin Z.) ed., I Comuni italiani nel regno crociato di Gerusalemme, Genova, Collana storica di Fonti e Studi diretta da Geo Pistarino, 1986.

Amato di Montecassino, Storia dei Noramnni, éd. V. de Bartholomaeis, Roma, Fonti per la storia d'Italia, 1935.

AmorouX-Mourad (Monique), Le Comté d'Edesse 1098-1150, Paris, Geuthner, 1988.

ANTONIADIs-BIBICOU (Hélène), Recherches sur les douanes a Byzance, Paris, Armand Colin, 1963.

AsHTOR (Eliyahu), A Social and Economic History of the Near East in the Middle Ages, London, 1976.

Ashtor (Eliyahu), Il regno dei Crociati e il commercio di Levante, in Airaldi-Kedar, "I Comuni italiani", pp. 15-56.

BACH (Erik), La cité de Genes au XIr siecle, Kobenhavn, 1955.

BALARD (Michel), Les Génois en Romanie entre 1204 et 1261. Recherches dans les minutiers notariaux génois, in "La mer Noire et la Romanie génoise (XIII'-XV* siècles)", London, Variorum Reprints, 1989, Étude 1. 
BALARD (Michel), La Romanie génoise (XIr-début du XV siècle), Roma, Bibliothèque des Écoles françaises d'Athènes et de Rome, fasc. 235, 1978.

BALARD (Michel), La popolazione di Famagosta all'inizio del secolo XIV, in "La storia dei Genovesi", Genova, 1984, IV, pp. 27-40.

BALARD (Michel), Les transports maritimes génois vers la Terre Sainte, in Airaldi-Kedar, "I Comuni italiani", pp. 143-174.

BALARD (Michel), Le film des navigations orientales de Genes au XIIr siecle, in Henri Dubois-Jean-Claude Hochquet-André Vauchez éd., "Horizons marins. Itinéraires spirituels", (2 vol., Paris, Publications de la Sorbonne, 1987), II, pp. 99-122.

BALleTto (Laura), In tema di marineria genovese, in R. Ragosta ed., "Le genti del mare Mediterraneo", (2 vol., Napoli, Lucio Pironti, 1981), I, pp. 357-396.

BALleTto (Laura), Fonti notarili genovesi del secondo Duecento per la storia del regno latino di Gerusalemme, in Airaldi-Kedar, "I Comuni italiani", pp. 175-279.

BASTARD DE PÉRÉ, Navires méditerranéens au temps de Saint Louis, in "Revue d'Histoire économique et sociale", 50 (1972), pp. 327356.

Belgrano (Luigi-T.), Documenti inediti riguardanti le due Crociate di San Ludovico IX re di Francia, Genova, 1859.

Belgrano (Luigi-T.), IMPERIALE DI SANT'ANGelo (Cesare), Annali genovesi di Caffaro e de' suoi continuatori, 5 vol., Roma, Fonti per la storia d'Italia, 1890-1929.

BRESC-BAUTIER (Genevieve), Le cartulaire du chapitre du SaintSépulcre de Jérusalem, Paris, Documents relatifs a l'histoire des croisades publiés par l'Académie des Inscriptions et Belles-Lettres, 1984.

BYRNE (Eugene-H.), Commercial contracts of the Genoese in the Syrian Trade of the XIIth Century, in "The Quarterly Journal of Economics", 31 (1917), pp. 128-170.

BYRNE (Eugene-H.), Genoese Trade with Syria in the twelth century, in "American Historical Review", 25 (1919-1920), pp. 191-219.

BYRNE (Eugene-H.), The Genoese colonies in Syria, in "The Crusades and other historical Essays presented to Dana C. Munro", New York, 1928, pp. 139-152.

BYRNE (Eugene-H.), Genoese Shipping in the XIIth and XIIIth centuries, Cambridge (Mass.), 1930. 
CAHEN (Claude), La Syrie du nord a l'époque des croisades et la principauté franque d'Antioche, Paris, Geuthner, 1940.

CAHEN (Claude), Un texte peu connu relatif au commerce oriental d'Amalfi au $X^{e}$ siecle, in "Turco-Byzantina et Oriens christianus", London, Variorum Reprints, 1974, étude 2 A.

CAHEN (Claude), Le commerce d'Amalfi avant, pendant et après la croisade, in "Comptes-rendus de l'Académie des Inscriptions et BellesLettres", Paris, 1977, pp. 291-301.

CAHEN (Claude), Orient et Occident au temps des croisades, Paris, Aubier, 1983.

CARDINI (Franco), Profilo di un crociato: Guglielmo Embriaco, in "Archivio storico italiano", 136 (1978), pp. 405-446.

CARO (Georg), Genova e la supremazia sul Mediterraneo (12571311), 2 vol. Genova, Atti della Società ligure di Storia patria, 1974-1975.

Citarella (Armand-O.), Patterns of Medieval Trade. The commerce of Amalfi before the Crusades, in "Journal of Economic History", 28 (1968), pp. 531-555.

DEsIMONI (Cornelio), Quatre titres des propriétés des Génois a Acre et d Tyr, in "Archives de l'Orient latin", 2 (1884), pp. 213-230.

FAVREAU-LILIE (Marie-Luise), Die Italiener im Heiligen Land vom ersten Kreuzzug bis zum Tode Heinrichs von Champagne (1098-1197), Amsterdam, Adolf M. Hakkert, 1989.

FaVReAU-LiLIE (Marie-Luise), Die Itolienische Levante-Piraterie und die Sicherheit des Seewege nach Syrien im 12 und 13 Jahrhundert, in "Vierteljahrschrift für Sozial und Wirtschaftgeschichte", 65/4 (1978), pp. 241-247.

FavreaU-Lilie (Marie-Luise), Graf Heinrich von Malta, Genua und Boemund IV von Antiochia. Eine Urkundenkritische Studie, in "Quellen und Forschungen aus italienischen Archiven und Bibliotheken", 58 (1978), pp. 181-215.

FAVREAU-LILIE (Marie-Luise), Friedenssicherung und Konfliksbegrenzung: Genua, Pisa und Venedig in Akkon, ca. 1200-1224, AiraldiKedar, "I Comuni italiani", pp. 429-447.

Favreau-Lille (Marie-Luise), Die italienischen Kirchen im Heiligen Land (1098-1291), in "Studi veneziani", 13 (1987), pp. 15-101.

Figliuolo (Bruno), Amalfi e il Levante nel Medioevo, in AiraldiKedar, "I Comuni italiani", pp. 571-664. 
FORCHERI (Giovanni), Navi e navigazione a Genova nel Trecento. Il "Liber Gazarie", Genova, Collana storica di Fonti e Studi diretta da Geo Pistarino, 1974.

Frankel (Rafael), I cippi confinari genovesi del kibbutz Shomrat, in Airaldi-Kedar, "I Comuni italiani", pp. 691-695.

Geanakoplos (Donald J.), Emperor Michael Palaeologus and the West 1258-1282, Cambridge (Mass.), 1959.

GoITEIN (S.D.), A Mediterranean Society. The Jewish Communities of the Arab World as portrayed in the Documents of the Cairo Geniza. I: Economic Foundations, Berkeley U.P.-Los Angeles, 1967.

HEYD (Wilhelm), Histoire du commerce du Levant au Moyen Age, 2 vol., Amsterdam 2, Adolf M. Hakkert, 1967.

IMPERIALE DI SANT'ANGElo (Cesare), Codice diplomatico della Repubblica di Genova, 3 vol., Roma, Istituto storico italiano per il Medioevo, 1936-1942.

JACOBY (David), The Kingdom of Jerusalem and the collapse of Hohenstaufen power in the Levant, in "Dumbarton Oaks Papers", 40 (1986), pp. 83-101.

JACOBY (David), Crusader Acre in the 13th century: urban layout and topography, in "Studies on the Crusader States and on Venetian Expansion", London, Variorum Reprints, 1989, étude V.

JACOBY (David), L'expansion occidentale dans le Levant: les Vénitiens d Acre dans la seconde moitié du XIII siecle, in "Journal of Medieval History", 3 (1977), pp. 225-264.

JACOBY (David), The rise of a new emporium in the Eastern Mediterranean: Famagusta in the late thirteenth century, in "Studies on the Crusader States and on Venetian Expansion", London, Variorum Reprints, 1989, étude VIII.

KeDAR, (Benjamin Z.), Mercanti genovesi in Alessandria d'Egitto negli anni sessanta del secolo $\mathrm{XI}$, in "Miscellanea di Studi storici" II, Genova, Collana di Fonti e Studi diretta da Geo Pistarino, 1983, pp. 19-30.

KEDAR, (Benjamin Z.), Genoa's Golden Inscription in the church of the Holy Sepulchre: a case for the defence, in Airaldi-Kedar, "I Comuni italiani", pp. 317-335.

KRUEGER (Hilmar-C.), Genoese merchants, their partnerships and investments 1155 to 1164, in "Studi in onore di Armando Sapori", (2 vol., Milano, 1957), I, pp. 257-272. 
KRUEGER (Hilmar-C.), Genoese merchants, their associations and investments 1155 to 1230, in "Studi in onore di Amintore Fanfani", (3 vol., Milano, 1962), I, pp. 415-426.

KRUEGER (Hilmar-C.), Navi e proprietd navale a Genova. Seconda meta del secolo XII, Genova, Atti della Società ligure di Storia patria, $\mathrm{XXV} / 1,1985$.

LISCIANDRELLI (Pasquale), Trattati e negoziazioni politiche della Repubblica di Genova (958-1797), Genova, Atti della Societa ligure di Storia patria, I, 1960.

MANFRONI (Camillo), Le relazioni fra Genova, l'impero bizantino ed $i$ Turchi, in "Atti della Società ligure di Storia patria", XXVIII (1898), pp. 575-856.

MAYER (Hans-E.)-FAVREAU (Marie Luise), Das Diplom Balduins I fur Genua und Genuas Goldene Inschrift in der Grabeskirche, in "Quellen und Forschungen aus italienischen Archiven und Bibliotheken", 55-56 (1976), pp. 22-95.

MOROZZO DELla RocCA (Raimondo)-Lombardo (Antonino), Documenti del commercio veneziano nei secoli XI-XIII, Torino, 1940.

Morozzo DELla RocCA (Raimondo)-Lombardo (Antonino), Nuovi documenti del commercio veneziano nei secoli XI-XIII, Venezia, 1953.

MÜLLER (Georg), Documenti sulle relazioni delle cittd toscane coll'Oriente cristiano, Firenze, 1879.

OTtEN-Froux (Catherine), Les Pisans en Orient de la premiere Croisade d 1406, thèse de III $^{\circ}$ cycle inédite (Paris, Université de Paris I, 1981).

Pegolotti (Francesco B.), La pratica della mercatura, éd. Allan Evans, Cambridge (Mass.), The Mediaeval Academy of America, 1936.

Pistarino (Geo), Genova e il Vicino Oriente nell 'epoca del Regno latino di Gerusalemme, in Airaldi-Kedar, "I Comuni italiani", pp. 57-139.

Pozza (Marco), Venezia e il Regno di Gerusalemme dagli Svevi agli Angioini, in Airaldi-Kedar, "I Comuni italiani", pp. 351-399.

PRAWER (Joshua), Histoire du royaume latin de Jerusalem, 2 vol., Paris, Éditions du CNRS, 1969-1970.

PRAWER (Joshua), The Italians in the Latin Kingdom, in "Crusader Institutions", Oxford, Clarendon Press, 1980, pp. 217-243. 
PraWER (Joshua), Colonialismo medievale. Il regno latino di Gerusalemme, Roma, Jouvence, 1982.

PRYOR (John), The naval architecture of Crusader Transport Ships, in "The Mariner's Mirror", 70 (1984), pp. 171-219, 275-292, 363-386.

QUeller (Donald E.)-KATELE (Irene B.), Venice and the conquest of the Latin Kingdom of Jerusalem, in "Studi veneziani", 12 (1986 ), pp. 15-43.

REY (E.G.), Les seigneurs de Giblet, in "Revue de l'Orient latin", 3 (1895), pp. 398-422.

RICHARD (Jean), Le comté de Tripoli sous la dynastie toulousaine, Paris, Geuthner, 1945.

RICHARD (Jean), Colonies marchandes privilégiées et marché seigneurial. La fonde d'Acre, in "Le Moyen Age", 1953, pp. 325-340.

RILEY-SMITH (Jonathan), The Knights of Saint John in Jerusalem and Cyprus (1100-1350), London, 1967.

RILEY-SMITH (Jonathan), Government in Latin Syria and the commercial privileges of foreign merchants, in D. Baker éd., "Relations between East and West in the Middle Ages", Edinburgh, University Press, 1973, pp. 109-132.

RöHRICHT (Reinhold), Regesta regni hierosolymitani 1097-1291, 2 vol., New-York 2, Burt Franklin, 1960.

SchAUBE (A.), Handelsgeschichte der romanischen Volker des Mittelmeergebietes bis zum Ende der Kreuzzuge, München-Berlin, 1906.

TAFEL (G.L.F.)-THOMAS (G.M.), Urkunden zur alteren Handelsund Staatsgeschichte der Republik Venedig mit besonderer Berücksichtigung auf Byzanz und die Levante, 3 vol., Wien, 1856-1857.

TANGHeroni (Marco), Pisa e il regno crociato di Gerusalemme, in Airaldi-Kedar, "I Comuni italiani", pp. 497-521.

WERNER (Karl-E.), Die Kreuzzugidee in Mittelalter, in "Wissenschaftliche Zeitschrift der Karl Marx Univesität Leipzig", 5 (1957-1958), pp. 135-140. 


\section{RÉSUMÉ}

Après un rappel des premiers contacts des villes maritimes italiennes avec le Levant, dans les décennies qui ont précédé les croisades, l'article étudie les modalités d'implantation des Italiens en Syrie-Palestine après 1098: les acteurs, la chronologie des concessions qui leur sont accordées, la répartition topographique des comptoirs dans les differents États nés de la croisade. Vient ensuite une étude détaillée des privilèges consentis aux marchands italiens: exemption des taxes, concessions financieres et foncieres. L'examen des conditions de navigation, des investissements, de la nature des trafics commerciaux complete cette étude qui dénonce le mythe d'un lien étroit entre les croisades et l'essor du commerce du Levant au Moyen Âge.

\section{SUMMARY}

The first relations of the Italian merchants with Syria-Palestina begin before the Crusades but were expanded after 1098. The author studies how the Italians settled in the Holy Land: who were they, when did they receive their concessions, where were established the colonies they were given in the various States founded in the Holy Land. The privileges they were granted are examined: immunity from taxes, financial concessions and real estates. The shipping, the investments and the nature of the trading activities demonstrate how mythical is the close link between the crusades and the growth of the Levant trade in the Middle Ages. 